\title{
FREQUENCY OF COMPLICATIONS FOLLOWING CATARACT SURGERY IN DIABETIC PATIENTS AT TERTIARY CARE HOSPITAL
}

\author{
Muhammad Bilal ${ }^{1}$, Shafqat Ali Shah ${ }^{2}$, Marina Murad $^{3}$, Saad Ali $^{4}$, Ammad Ali $^{5}$, Muhammad Ayub ${ }^{6}$
}

\section{ABSTRACT:}

\section{OBJECTIVES:}

To determine the frequency of complications following cataract surgery in diabetic patients admitted in the ophthalmology unit.

\section{METHODOLOGY:}

A prospective descriptive interventional case series study was conducted after approval of the ethical committee, from June 2017-June 2020 at the Ophthalmology department MTI-MMC. A total of 129 patients from either gender were enrolled in study. All the study patients went through detailed history and complete ocular examination. After necessary investigations, surgical procedure was carried out. Results were analyzed through the SPSS-24 version.

\section{RESULTS:}

Out of the total 129 eyes of the diabetic patients, fifty-nine (45.7\%) were males and seventy (54.3\%) were females with a ratio of 1:1.2. Uveitis leads the chart in complications found in twenty (15.50\%) eyes while PODR being the least common found in only ten (7.75\%) eyes. Worse visual acuity was observed in fourteen (10.85\%) eyes. Striate keratopathy and posterior capsule opacification were found in sixteen (12.40\%) and fifteen (11.62\%) eyes respectively. Among the patients, $15.7 \%$ were having more than one complication during follow-up visits and eighty-eight (68.2\%) eyes were found to have none complication. The age group 51-60 years observed frequent complications as compared to other groups. Similarly female gender (38.57\%) has frequent complications as compared to males $(2.7 \%)$.

\section{CONCLUSION:}

The study concludes Uveitis as the most common complication observed in $15.50 \%$ of the eyes while worse visual acuity (10.85\%) and progression of diabetic retinopathy (7.75\%) being the least common. Striate keratopathy was found in $12.40 \%$ while posterior capsule opacification in $11.62 \%$ of the eyes.

KEYWORDS: Cataract, Diabetes Mellitus, Uveitis, Posterior Capsule Opacification, Striate Keratopathy, Progression Diabetic Retinopathy

How to cite this article:

Bilal M, Shah SA, Murad M, Ali S, Ali A, Ayub M. Frequency of Complications Following Cataract Surgery in Diabetic Patients at Tertiary Care Hospital. J Gandhara Med Dent Sci. 2022;9(1): 75-81

https://doi.org/10.37762/jgmds.9-1.157 


\section{Correspondence:}

${ }^{1}$ Muhammad Bilal, Assistant Professor, Ophthalmology, Mardan Medical Complex-Mardan

(N): $\quad+92-333-9210579$

$\otimes: \quad$ drbilal80@yahoo.com

${ }^{2}$ Associate Professor Ophthalmology Unit Mardan Medical Complex, Mardan

${ }^{3}$ Medical Officer, Ophthalmology Unit, Mardan Medical Complex, Mardan

${ }^{4}$ District Medical Officer, Mardan Medical Complex, Mardan ${ }^{5}$ Medical Officer ICU, Mardan Medical Complex, Mardan ${ }^{6}$ Postgraduate Trainee, Junior Registrar, Lady Reading Hospital, Peshawar

\section{INTRODUCTION:}

The World Health Organization estimated that cataract remains the leading cause of blindness, approximately affecting 285 million people worldwide ${ }^{1}$. Cataract is a safe and cost-effectively treatable condition ${ }^{2}$. It is estimated that more than 1000 people become blind annually due to diabetes related complications ${ }^{3}$. Diabetes Mellitus (DM) is an important determinant for cataract and scientific research has revealed a causal biochemical relationship between cataract and DM development ${ }^{4}$. The United Kingdom National Survey of Cataract Surgery found that patients with no ocular comorbidities achieved post-operative VA of $6 / 12$ or better $^{5}$. Patients with diabetes are $25 \%$ more likely to become blind than non-diabetics ${ }^{6}$. Surgery in diabetic patients is more frequently accompanied by postoperative inflammation, infectious endophthalmitis and posterior capsular opacification $^{7,8}$. Ivanic et al reported postoperative keratopathy in $28 \%$, uveitis in $20 \%$, and posterior capsular opacification in $22 \%$ (mild) and $16 \%$ (severe), progression of diabetic retinopathy in $14 \%$ and development of diabetic maculopathy in $6 \%$ of patients ${ }^{9}$. At the same time progression of retinopathy, rubeosis iridis, increased incidence and severity of macular edema with ultimate increase in visual morbidity is also reported post-operatively ${ }^{10}$. The cataract related visual morbidity in diabetic population at an earlier age has a significant impact on the working age individuals, which may have ultimate profound adverse effect on the socioeconomic conditions of our society. Furthermore, the increasing incidence of DM in developing countries like Pakistan necessitates an assessment of the surgical outcome of diabetic cataract among the affected subjects. The aim of this study was to investigate the frequency of common complications following cataract surgery in diabetic patients. The rationale of the study is that, if in our study the frequency of complications following cataract surgery in diabetic patients comes out significantly higher as compared to other studies, then it can lead to reconsideration of the existing guidelines regarding the pre-operative assessment, operative techniques and post-operative care of the diabetic patients undergoing cataract surgery.

\section{METHODOLOGY:}

A prospective descriptive interventional case series study was conducted after approval of the ethical committee, from June 2017-June 2020 at the Department of Ophthalmology, Medical Teaching Institution Mardan Medical Complex Mardan (MTIMMC). One hundred and twenty nine eyes of 129 patients were selected for this study. Sample size was calculated using 14\% proportion of progression of diabetic retinopathy, $6 \%$ margin of error and $95 \%$ confidence of interval using W.H.O sample size calculator through non-probability sampling. All diabetic patients with duration of diabetes $>5$ years and cataracts having best corrected visual activity (BCVA) of $<6 / 18$ were included. Eyes with Mild, Moderate or Severe NPDR or PDR stages of diabetic retinopathy were included. Patients from both gender and age more than 40 years were included. Patients with traumatic and complicated cataract with no comorbidities through history and slit lamp examination were excluded. All the patients meeting the inclusion criteria were admitted in the eye ward through the Out Patient Department (OPD). Diagnostic criteria for inclusion was known diabetics or fasting plasma glucose level of $>126$ $\mathrm{mg} / \mathrm{dl}$ or random plasma glucose level $>200 \mathrm{mg} / \mathrm{dl}$ on laboratory investigations and opacification in the crystalline lens with baseline BCVA of $<6 / 18$ and Diabetic Retinopathy (DR) of mild, moderate, severe NPDR or PDR stage. Informed written consent was obtained from all the study cases. The patient"s history and visual acuity was recorded at presentation. Both eyes of the patient including a detailed fundus examination were performed by a consultant ophthalmologist. Routine investigations were performed for all the study patients on the day of admission. The patients were operated on the next operation theater list. Manual Small Incision Cataract Surgery (MSICS) was performed by a single well-experienced surgeon. After being operated, all the patients were followed at $1^{\text {st }}$ postoperative day to detect Striate Keratopathy (SK) and Uveitis (Uv) and then on $40^{\text {th }}$ postoperative day to detect Worse Visual Outcome (WVO), Posterior Capsular Opacification (PCO) and Progression of 
Diabetic Retinopathy (PODR). All the follow-up assessments were carried out under supervision of the single ophthalmologist. All the above-mentioned information including the patients ${ }^{\text {ee }}$ name, age, sex, address and duration of diabetes were recorded in a proforma. Strict exclusion criteria were followed to control confounders and bias in the study results. Results were stratified among age, sex and duration of DM to see the effect modification. All the results were presented in the form of tables.

\section{RESULTS:}

One hundred and twenty nine eyes of 129 diabetic patients above 40 years of age diagnosed as having cataract and fulfilling the inclusion criteria were included in this study. All the study patients completed the 40 days follow-up period. The minimum age at which the patient presented was 42 years while the oldest patient was 85 years of age with a mean of 57.9 and $\mathrm{SD} \pm 8.7$. Sixty one (47.3\%) patients presented in the age group of 51-60 years, making it the most common decade of presentation for diabetic patients with cataract. Details regarding the age of our study population are given in Table 1 . Among the study patients, the minimum duration of diabetes was 5 years while the maximum was 22 years, the mean of 9.7 and $\mathrm{SD} \pm 3.9$. Sixty-nine
$(53.6 \%)$ patients presented with duration of diabetes ranging from 6 to 10 years. Details regarding duration of DM are given in Table 2. Out of the total 129 patients, Fifty-nine (45.7\%) were males and seventy $(54.3 \%)$ were females with a ratio of $1: 1.2$. Regarding complications out of the total 129 patients, Uv was the most common complication found in twenty $(15.50 \%)$ eyes, while PODR being least commonly found in only ten $(7.75 \%)$ eyes. WVO was observed in fourteen $(10.85 \%)$ eyes, hence there was improvement in visual acuity in $89.15 \%$ of the study cases. SK and PCO were found in sixteen $(12.40 \%)$ and fifteen $(11.62 \%)$ eyes respectively. Among the study patients, $15.7 \%$ were found to have more than one complication during their follow-up visits. Eighty-eight $(68.2 \%)$ eyes were found to have none of the defined complications (Table 3). Complications were observed more frequently in the age group 51-60 years as compared to other age groups (Table 4). Among the study cases, fourteen $(23.72 \%)$ male and twenty-seven (38.57\%) female patients were observed to have complications following cataract surgery. Hence the female gender appeared to have more frequent complications as compared to male (Table 5). The frequency of complications was highest in patients with 10 years duration of diabetes.

Table 1: Age Distribution of the Study Population $(n=129)$

\begin{tabular}{|ccc|}
\hline Age (Years) & Frequency (n) & Percent (\%) \\
\hline $41-50$ & 32 & 24.8 \\
$51-60$ & 61 & 47.3 \\
$61-70$ & 26 & 20.2 \\
$71-80$ & 8 & 6.2 \\
$81-90$ & 2 & 1.6 \\
\hline Total & 129 & 100.0 \\
\hline
\end{tabular}

Table 2: Duration of Diabetes Mellitus (DM)

\begin{tabular}{|ccc|}
\hline Duration of DM (Years) & Frequency (n) & Percent (\%) \\
\hline 5.00 & 20 & 15.5 \\
$6-10$ & 69 & 53.6 \\
$11-15$ & 26 & 20.2 \\
$16-20$ & 12 & 9.4 \\
$>20$ & 2 & 1.6 \\
\hline Total & 129 & 100.0 \\
\hline
\end{tabular}

Table 3: Frequency of Complications

\begin{tabular}{|lcc|}
\hline Complications & Frequency (n) & Percent (\%) \\
\hline WVO & 14 & 10.85 \\
SK & 16 & 12.40 \\
Uv & 20 & 15.50 \\
PCO & 15 & 11.62 \\
PODR & 10 & 7.75 \\
\hline
\end{tabular}


$\mathrm{WVO}=$ worse visual outcome; $\mathrm{SK}=$ striate keratopathy; $\mathrm{Uv}=$ uveitis; $\mathrm{PCO}=$ posterior capsular opacification; PODR=progression of diabetic retinopathy

Table 4: Distribution of Complications in Different Age Groups

\begin{tabular}{|c|c|c|c|c|c|c|}
\hline \multirow[b]{2}{*}{ Complications } & \multicolumn{5}{|c|}{ Age Groups (Years) } & \multirow[b]{2}{*}{ Total } \\
\hline & $41-50$ & $51-60$ & $61-70$ & $71-80$ & $81-90$ & \\
\hline $\mathrm{WVO} / \mathrm{SK} / \mathrm{PCO}$ & 0 & 2 & 0 & 0 & 0 & 2 \\
\hline WVO/PODR & 0 & 4 & 0 & 0 & 2 & 6 \\
\hline SK & 0 & 2 & 2 & 0 & 0 & 4 \\
\hline Uv & 1 & 4 & 2 & 1 & 0 & 8 \\
\hline PCO & 2 & 3 & 2 & 0 & 0 & 7 \\
\hline PODR & 0 & 0 & 2 & 0 & 0 & 2 \\
\hline Nil & 29 & 38 & 14 & 7 & 0 & 88 \\
\hline $\mathrm{Uv} / \mathrm{SK}$ & 0 & 2 & 2 & 0 & 0 & 4 \\
\hline Uv/PODR & 0 & 2 & 0 & 0 & 0 & 2 \\
\hline $\mathrm{WVO} / \mathrm{Uv} / \mathrm{SK} / \mathrm{PCO}$ & 0 & 4 & 2 & 0 & 0 & 6 \\
\hline Total & 32 & 61 & 26 & 8 & 2 & 129 \\
\hline
\end{tabular}

$\mathrm{WVO}=$ worse visual outcome; $\mathrm{SK}=$ striate keratopathy; $\mathrm{Uv}=$ uveitis; $\mathrm{PCO}=$ posterior capsular opacification; $\quad \mathrm{PODR}=$ progression of diabetic retinopathy

Table 5: Distribution of Complications in Both Genders

\begin{tabular}{|c|c|c|c|}
\hline \multirow[t]{2}{*}{ Complications } & \multicolumn{2}{|c|}{ Gender } & \multirow[t]{2}{*}{ Total } \\
\hline & Male & Female & \\
\hline WVO/PODR & 2 & 4 & 6 \\
\hline SK & 0 & 4 & 4 \\
\hline Uv & 3 & 5 & 8 \\
\hline WVO/SK/PCO & 0 & 2 & 2 \\
\hline $\mathrm{PCO}$ & 5 & 2 & 7 \\
\hline PODR & 0 & 2 & 2 \\
\hline WVO/Uv/SK/PCO & 2 & 4 & 6 \\
\hline Uv/SK & 2 & 2 & 4 \\
\hline Uv/PODR & 0 & 2 & 2 \\
\hline Nil & 45 & 43 & 88 \\
\hline Total & 59 & 70 & 129 \\
\hline
\end{tabular}

$\mathrm{WVO}=$ worse visual outcome; $\mathrm{SK}=$ striate keratopathy; $\mathrm{Uv}=$ uveitis; $\mathrm{PCO}=$ posterior capsular opacification; $\mathrm{PODR}=$ progression of diabetic retinopathy

\section{DISCUSSION :}

Surgical intervention is the treatment of choice globally in cases of cataract. MSICS was performed for all patients undergoing cataract extraction. It is cost-effective, requires less instrumentation and results are comparable to phacoemulsification and that is why this procedure is also called poor man's phaco $^{11}$. Cataract surgery should be performed earlier in diabetic patients before development of diabetic maculopathy or retinopathy compared to non-diabetics ${ }^{12}$. Mean age of diabetic patients prior to surgery of 57.9 years in this study is almost similar to that reported by Grauslud (59.3 years) and Ching et al (56.7 years) in their study population ${ }^{13,14}$. Mean duration of DM prior to surgery was 9.7 years, which is lower than 13 years ${ }^{15}$. A recent study has reported WVO in $15.8 \%$ of the diabetic patients followed for 6 months after cataract surgery. Hence there was improvement in post-operative $\mathrm{VA}$ in $84.2 \%$ of the cases ${ }^{16}$. In contrast, the results are encouraging in our study in which WVO was observed in $10.85 \%$ of the cases with subsequent improvement in post-operative VA in $89.15 \%$ of the patients. This difference in results may be due to the short follow up of 40 days in our study. This finding supports previous reports that diabetic patients with maculopathy and retinopathy may have valuable visual improvement after cataract surgery ${ }^{17}$. A study reported WVO in $16.2 \%$ and improvement in VA in $83.8 \%$ of the eyes followed for up to 3 years ${ }^{18}$. Similarly, a study had reported WVO in $15 \%$ with improvement in VA in $85 \%$ of the cases ${ }^{19}$. Following ocular surgery, recurrent corneal erosions and striate keratopathy are more common in diabetics than in non-diabetics. Ivancic et al had reported postoperative keratopathy in $28 \%$ of the diabetic patients, which is much higher than $12.40 \%$ in our study ${ }^{9}$. The post-operative complications were more frequent among diabetic patients especially the posterior capsular rent, striate keratopathy $(21.21 \%)$ and fibrinous exudation ${ }^{16}$. The association of DM and Uv has long been known. Like cataract, 
retinopathy and glaucoma, DM also increases the chances of uveitis. A study showed DM in $6 \%$ of cases with anterior uveitis ${ }^{20}$. In our study Uv was detected in $15.50 \%$ of the patients following cataract surgery. A study reported Uv in $12 \%$ of the cases after cataract surgery ${ }^{16}$. Another study reported intraocular inflammation and its sequelae as the most common complication in their study ${ }^{21}$. Similarly, inflammatory reactions and bleeding, which resulted in post-operative keratopathy, fibrinous uveitis and posterior capsule opacity, were the common complications of cataract surgery amongst diabetics ${ }^{22}$. Opacification of the posterior capsule which is thought to be caused by the postoperative proliferation of lens epithelial cells in the capsular bag remains the most frequent complication of cataract extraction with IOL implantation ${ }^{19,20}$. The patients with diabetes mellitus develop PCO earlier after cataract surgery than their non-diabetic counterparts ${ }^{21}$. Only $11.62 \%$ of our patients develop PCO after cataract surgery which is lower than $16 \%$ reported by Ivancic et al but higher than $6.06 \%$ reported in another study ${ }^{9,16}$. The PODR is suggested to be caused by the disruption of the blood retinal barrier during surgery and the enhanced inflammation following cataract extraction in diabetic patients. PODR was seen in $7.75 \%$ of eyes in our study. This percentage is quite lower than that seen in many recent series of phacoemulsification and extracapsular cataract extraction (ECCE) in diabetic patients $(43 \%)^{23}$ however, conclusions drawn from comparison between studies with different patient populations and levels of preoperative retinopathy were not free of errors. The PODR after intracapsular cataract extraction (ICCE) and ECCE in diabetic patients has been well documented ${ }^{24}$. One researcher reported that diabetic patients without retinopathy were more likely to show progression of retinopathy than patients with mild-to-moderate $\mathrm{DR}^{24}$, but others reported that severe NPDR and PDR were the strongest factors associated with retinopathy progression $^{25}$. The rate of retinopathy progression and other complications after cataract surgery were reported to be influenced by some variables such as age ${ }^{26}$, severity of preoperative $\mathrm{DR}^{27}$, duration of diabetes $^{28}$, and levels of $\mathrm{HbAl}^{25}$. Our results supported that the rate of complications was higher in patients aged 51-60 years, since this was the commonest decade of presentation of the diabetic patients. Similarly, complications were more frequent in patients with 10 years duration of diabetes. Furthermore, in our study the complication rate was higher in the female gender compared to the male patients. Diabetics with co-existing cataract presenting for surgery have an overall good visual outcome and cataract surgery should not be discouraged in these patients. However, proper preoperative assessment is needed and extra precaution needs to be taken intra-operatively as well as adequate postoperative monitoring is recommended. In addition, treatment of existing diabetic retinopathy or maculopathy should be performed to improve visual outcome and reduce post-operative complications. Although the frequency of post-operative complications was lower than most of the studies conducted world-wide, these results cannot be extrapolated to the general population due to smaller sample size and short follow-up, therefore we recommend better randomized studies on a larger sample size with longer follow-up.

\section{CONCLUSION:}

The most common complication found in our study was Uv accounting for $15.50 \%$ of the cases, followed by SK (12.40\%), PCO (11.62\%), WVO $(10.85 \%)$ and PODR being least common observed in only $10(7.75 \%)$ eyes. Complications were observed more frequently in female gender and in the age group of 51-60 years. The frequency of complications was highest in patients with 10 years duration of diabetes and $15.7 \%$ of the eyes were found to have more than one complication.

\section{CONFLICT OF INTEREST: None}

\section{FUNDING SOURCES: None}

\section{REFERENCES:}

1. Katibeh $\mathrm{M}$, Behboudi $\mathrm{H}$, Moradian $\mathrm{S}$, Alizadeh Y, Beiranvand R, Sabbaghi H, et al. Rapid assessment of avoidable blindness and diabetic retinopathy in Gilan Province, Iran. Ophthalmic Epidemiol. 2017;24(6):381-7.

2. Lundström M, Goh PP, Henry Y, Salowi MA, Barry $\mathrm{P}$, Manning $\mathrm{S}$, et al. The changing pattern of cataract surgery indications: 5-year study of 2 cataract surgery databases. Ophthalmology. 2015;122(1):31-8.

3. Cheng F, Shan L, Song W, Fan P, Yuan H. Distance and near visual impairment in rural Chinese adults in Kailu, Inner Mongolia. Acta Ophthalmol. 2016;94(4):407-13.

4. Li X, Liu W, Huang X, Xiong J, Wei X. Interaction of $\mathrm{AR}$ and $\mathrm{iNOS}$ in lens epithelial cell: a new pathogenesis and 
potential therapeutic targets of diabetic cataract. Arch Biochem Biophys. 2017;615:44-52.

5. Day AC, Donachie PH, Sparrow JM, Johnston RL. United Kingdom national ophthalmology database study of cataract surgery: report 3: pseudophakic retinal detachment. Ophthalmology. 2016;123(8):1711-5.

6. Mumtaz SN, Fahim MF, Arslan M, Shaikh SA, Kazi U, Memon MS. Prevalence of diabetic retinopathy in Pakistan: a systematic review. Pak J Med Sci. 2018;34(2):493.

7. Szakáts I, Sebestyén M, Tóth É, Purebl G. Dry eye symptoms, patient-reported visual functioning, and health anxiety influencing patient satisfaction after cataract surgery. Curr Eye Res. 2017;42(6):832-6.

8. Llop SM, Papaliodis GN. Cataract surgery complications in uveitis patients: a review article. Semin Ophthalmol. 2018;33(1):64-9.

9. Peterson SR, Silva PA, Murtha TJ, Sun JK. Cataract surgery in patients with diabetes: management strategies. Semin Ophthalmol. 2018;33(1):75-82.

10. Kelkar A, Kelkar J, Mehta H, Amoaku W. Cataract surgery in diabetes mellitus: a systematic review. Indian $\mathrm{J}$ Ophthalmol. 2018;66(10):1401.

11. Zhao LQ, Cheng JW. A systematic review and meta-analysis of clinical outcomes of intravitreal anti-VEGF agent treatment immediately after cataract surgery for patients with diabetic retinopathy. J Ophthalmol. 2019;2019:1-10.

12. Ngweme G, Bambi MT, Lutete LF, Kilangalanga NJ, Hopkins A, Stachs O, et al. Ophthalmic ultrasonography in SubSaharan Africa-a Kinshasa experience. Diagnostics. 2021;11(11):2009.

13. Do VQ, McCluskey P, Palagyi A, Stapleton FJ, White A, Carnt N, et al. Are cataract surgery referrals to public hospitals in Australia poorly targeted?. Clin Exp Ophthalmol. 2018;46(4):364-70.

14. Lee GI, Lim DH, Chi SA, Kim SW, Shin DW, Chung TY. Risk factors for intraocular lens dislocation after phacoemulsification: a nationwide population-based cohort study. Am J Ophthalmol. 2020;214:86-96.

15. Song E, Qian DJ, Wang S, Xu C, Pan CW. Refractive error in Chinese with type 2 diabetes and its association with glycaemic control. Clin Exp Optom. 2018;101(2):2139.
16. Silpa-Archa S, Papirachnart A, Singhanetr P, Preble JM. Risk factors for endophthalmitis after cataract surgery in diabetic patients: a case control study. Int $\mathbf{J}$ Ophthalmol. 2019;12(3):417.

17. Ajiya A, Abdullahi H, Shuaibu IY. Clinicopathologic profile of sinonasal neoplasia in Kano, Northwestern Nigeria: a 10-year single-institution experience. Ann Afr Med. 2020;19(3):191.

18. Grzybowski A, Kanclerz P, Huerva V, Ascaso FJ, Tuuminen R. Diabetes and phacoemulsification cataract surgery: difficulties, risks and potential complications. J Clin Med. 2019;8(5):716.

19. Pukl SS, Valentinčič NV, Urbančič M, Grčar II, Grčar R, Pfeifer V, et al. Visual acuity, retinal sensitivity, and macular thickness changes in diabetic patients without diabetic retinopathy after cataract surgery. J Diabetes Res. 2017;2017:1-8.

20. Denniston AK, Chakravarthy U, Zhu H, Lee AY, Crabb DP, Tufail A, et al. The UK Diabetic Retinopathy Electronic Medical Record (UK DR EMR) Users Group, Report 2: real-world data for the impact of cataract surgery on diabetic macular oedema. Br $\mathrm{J}$ Ophthalmol. 2017;101(12):1673-8.

21. Watanabe T, Keino H, Nakayama K, Taki W, Echizen N, Okada AA. Clinical features of patients with diabetic anterior uveitis. $\mathrm{Br}$ J Ophthalmol. 2019;103(1):78-82.

22. Gaskin GL, Pershing S, Cole TS, Shah NH. Predictive modeling of risk factors and complications of cataract surgery. Eur $\mathrm{J}$ Ophthalmol. 2016;26(4):328-37.

23. Wu S, Tong N, Pan L, Jiang X, Li Y, Guo $\mathrm{M}$, et al. Retrospective analyses of potential risk factors for posterior capsule opacification after cataract surgery. J Ophthalmol. 2018;2018:1-7.

24. Singh RP, Lehmann R, Martel J, Jong K, Pollack A, Tsorbatzoglou A, et al. Nepafenac $0.3 \%$ after cataract surgery in patients with diabetic retinopathy: results of 2 randomized phase 3 studies. Ophthalmology. 2017;124(6):776-85.

25. Sasongko MB, Rogers S, Constantinou M, Sandhu SS, Wickremasinghe SS, AlQureshi S, et al. Diabetic retinopathy progression 6 months post-cataract surgery with intravitreous bevacizumab vs triamcinolone: a secondary analysis of the DiMECAT trial. Clin Exp Ophthalmol. 2020;48(6):793-801. 
26. Balta O, Sungur G, Acar MA, Kosker M, Yakin M, Ornek F. Long-term results of cataract surgery in patients with anterior uveitis. Int Ophthalmol. 2018;38(4):1399407.

27. Shaikh AR, Mirani AH, Memon MS, Fahim MF. Visual outcome after phacoemulsification with lens implant in diabetic and non-diabetic patients: a comparative study. Pak J Med Sci. 2017;33(3):691.

28. Chu CJ, Johnston RL, Buscombe C, Sallam $\mathrm{AB}$, Mohamed Q, Yang YC, et al. Risk factors and incidence of macular edema after cataract surgery: a database study of 81984 eyes. Ophthalmology. 2016;123(2):316-23.

\section{CONTRIBUTORS}

1. Muhammad Bilal - Concept \& Design; Data Analysis/Interpretation; Critical Revision; Supervision; Final Approval

2. Shafqat Ali Shah - Data Acquisition; Data Analysis/Interpretation; Drafting Manuscript

3. Marina Murad - Data Acquisition; Data Analysis/Interpretation; Drafting Manuscript; Critical Revision

4. Saad Ali - Data Acquisition; Data Analysis/Interpretation; Drafting Manuscript; Critical Revision

5. Ammad Ali - Concept \& Design; Data Acquisition; Data Analysis/Interpretation; Drafting Manuscript; Supervision; Final Approval

6. Muhammad Ayub - Data Acquisition; Data Analysis/Interpretation; Drafting Manuscript

LICENSE: JGMDS publishes its articles under a Creative Commons Attribution Non-Commercial Share-Alike license (CC-BY-NC-SA 4.0). COPYRIGHTS: Authors retain the rights without any restrictions to freely download, print, share and disseminate the article for any lawful purpose. It includes scholarly networks such as Research Gate, Google Scholar, LinkedIn, Academia.edu, Twitter, and other academic or professional networking sites. 